\title{
The Anticancer Effects of Radachlorin-mediated Photodynamic Therapy in the Human Endometrial Adenocarcinoma Cell Line HEC-1-A
}

\author{
SU-MI KIM ${ }^{1}$, YUN-HEE RHEE ${ }^{2}$ and JONG-SOO KIM ${ }^{1}$ \\ ${ }^{1}$ Department of Obstetrics and Gynecology, College of Medicine, and \\ ${ }^{2}$ Beckman Laser Institute Korea, Dankook University, Cheonan, Republic of Korea
}

\begin{abstract}
Aim: We investigated the effect of photodynamic therapy (PDT) using radachlorin on invasion, vascular formation and apoptosis by targeting epidermal growth factor receptor (EGFR)/vascular endothelial growth factor receptor 2 (VEGFR2) signaling pathways in the HEC-1-A endometrial adenocarcinoma cell line. Materials and Methods: To investigate the apoptotic pathway, we performed the 3-(4,5dimethylthiazol-2-yl)-2,5-diphenyltetrazolium bromide (MTT) assay, terminal deoxynucleotidyl transferase dUTP nick-end labeling (TUNEL) assay, and western blot analysis. We also evaluated the effects of PDT on tubular capillary formation in and invasion by HEC-1-A cells with a tube formation assay, invasion assay, prostaglandin E2 (PGE2) assay, and western blot analysis. Results: PDT had anticancer effects on HEC-1-A through activation of the intrinsic pathway of apoptosis via caspase-9 and poly-(ADP-ribose) polymerase (PARP). PDT also inhibited tubular capillary formation in and invasion by HEC-1-A under VEGF pretreatment, that resulted from down-regulation of VEGFR2, EGFR, Ras homolog gene family/ member A (RhoA) and PGE2. These results are indicative of the specificity of radachlorinmediated PDT to VEGF. Conclusion: The major advantage of radachlorin-mediated PDT is its selectivity for cancer tissue while maintaining adjacent normal endometrial tissue. Therefore, radachlorin-mediated PDT might offer high anticancer efficacy for endometrial adenocarcinoma and an especially useful modality for preserving fertility.
\end{abstract}

Correspondence to: Professor Jong-Soo Kim, Ph.D., Department of Obstetrics \& Gynecology, College Of Medicine, Dankook University, 359 Manhyangro, Dongnam-gu, Cheonan, Chungcheongnam-do, 330-715, Republic of Korea. Tel: +82 415506159, Fax: +82 415563878, e-mail: soo8541@hanmail.net

Key Words: Radachlorin, photodynamic therapy, endometrial adenocarcinoma cell line, HEL-1-A, EGFR, apoptosis.
Endometrial cancer is the third most common malignancy in Korea and the most common gynecological cancer in the United States $(1,2)$. The burden of endometrial cancer has increased with an annual increase in incidence and mortality. Approximately $80 \%$ of endometrial cancers are diagnosed at an early stage $(3,4)$ and $3-14 \%$ of all cases are diagnosed before 40 years of age (5). Conservative therapy has emerged as an alternative to surgery in the management of young patients with early-stage endometrial cancer who wish to retain their fertility. Hormonal agents, such as progestin, and gonadotropin-releasing hormone analogs are often used in such cases (6). However, maintenance treatment with hormonal agents precludes pregnancy; moreover, the therapeutic effect appears to be inadequate. Therefore, development of new treatment modalities for endometrial cancer is required for women who wish to preserve their fertility.

Epidermal growth factor receptor (EGFR) and vascular endothelial growth factor receptor 2 (VEGFR2) are tyrosine kinase receptors that play a key role in cancer development and progression. Activation of EGFR and VEGFR2 triggers the phosphorylation of multiple proteins, including those of the phosphatidylinositol-3-kinase/serine/threonine kinase (PI3K/AKT) and mitogen-activated protein kinase (MAPK) pathways which are involved in cell survival, apoptosis and angiogenesis $(7,8)$. Overexpression of EGFR and VEGFR2 is frequently observed in many cancer types $(9,10)$. Abnormal activation of EGFR and VEGFR2 correlates with poor prognosis and chemoresistance $(11,12)$. Because of potential interactions and their well-established role in cancer growth and angiogenesis, inhibition of both EGFR and VEGFR2 signaling pathways might improve the outcome of patients with endometrial cancer (13).

Photodynamic therapy (PDT) is becoming widely accepted as a potential treatment for cancer and some nonmalignant diseases (14). Some studies indicated the potential therapeutic role of PDT in patient with early-stage endometrial cancer $(15,16)$. PDT involves the use of a 
A

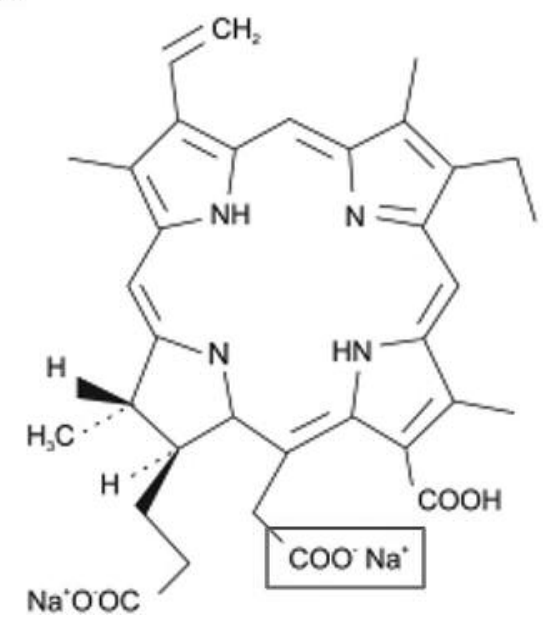

B

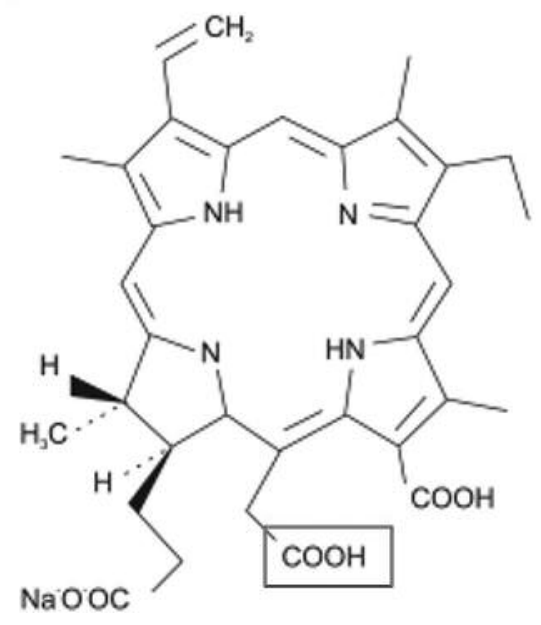

Figure 1. Structure of radachlorin ${ }^{\circledR}$. A: Major component. sodium chlorine $e_{6}$; B: one of the minor components, sodium chlorine $e_{6}$.

compound called a photosensitizer that can be excited by a specific wavelength of light. The activated photosensitizer then interacts with molecular oxygen to produce cytotoxic singlet oxygen and other reactive oxygen species that destroy target cells (17). Radachlorin, a mixture of the sodium salts of chlorine e6, chlorine p6 and purpurin 18, is a promising second-generation photosensitizer (Figure 1). Radachlorin has better light penetration of target tissue, as compared to first-generation photosensitizers (18). The anticancer effects of PDT using radachlorin in some in vitro and in vivo cancer models have been reported (19-22); however, the potential of radachlorin-mediated PDT for the treatment of endometrial adenocarcinoma remains unclear.

In the present study, we investigated the effect of radachlorin-mediated PDT on invasion, vascular formation and apoptosis by targeting EGFR/VEGFR2 signaling pathways in the HEC-1-A endometrial adenocarcinoma cell line.

\section{Materials and Methods}

Cell lines and cell culture. The human endometrial adenocarcinoma cell line HEC-1-A was purchased from the American Type Culture Collection (Manassas, VA, USA). HEC-1-A was maintained in McCoy's 5A medium (Life Technologies, Grand Island, NY, USA) containing $10 \%$ fetal bovine serum and $1 \%$ streptomycin-penicillin (Corning, Carlsbad, CA, USA).

Photosensitizer and light source. Radachlorin (RADA-PHARMA Co, Ltd., Moscow, Russia) was dissolved in dimethylsulfoxide (DMSO) to obtain $1 \mathrm{mM}$ stock solution, which was stable in solution at $0 \pm 4^{\circ} \mathrm{C}$ in the dark. Working drug solutions $(0.39-200 \mu \mathrm{g} / \mathrm{ml})$ were prepared by diluting the stock solution with serum-free medium. A diode laser device (WonTech, Korea; power output $50 \mathrm{~mW}$ ) was the source of monochromatic red light $(660 \mathrm{~nm})$ for PDT used in this study.
Photodynamic treatment and observation of cell morphology. HEC1-A cells were seeded at a density of $5 \times 10^{4}$ cells per well in 96-well flat-bottomed micro titer plates (SPL Life Science, Daejeon, Korea). After $24 \mathrm{~h}$, cells were incubated with different concentrations of radachlorin for $4 \mathrm{~h}$ in the dark. After removing the drug and washing with phosphate-buffered saline (PBS), the treated cells was irradiated using a light-emitting diode at $25 \mathrm{~J} / \mathrm{cm}^{2}$. All irradiations were performed at room temperature $\left(25^{\circ} \mathrm{C}\right)$. Controls for each experiment were cells exposed to PDT light (at each light dose) without radachlorin. Cells were observed at 24 and $48 \mathrm{~h}$ under an inverted microscope (BX51; Olympus, Miami, FL, USA.). Cytototoxicity by PDT results were expressed as the percentage of treated cell viability in comparison to controls. All experiments were repeated three times.

Assessment of cell viability: 3-(4, 5-dimethylthiazol-2-yl)-2, 5diphenyltetrazolium bromide (MTT) assay. Cell survival was evaluated by MTT assay. In brief, culture medium was removed, and control/treated cells were incubated in medium with $0.5 \mathrm{mg} / \mathrm{ml} \mathrm{MTT}$ solution (Sigma-Aldrich Corporation, St. Louis, MO, USA) for $3 \mathrm{~h}$ at $37^{\circ} \mathrm{C}$ to allow MTT metabolism. The resulting formazan crystals were dissolved with $100 \mathrm{~mol} / \mathrm{l}$ of DMSO (Life technologies, Grand Island, NY, USA) and the absorbance was measured at $540 \mathrm{~nm}$ using an enzyme-linked immunosorbent assay (ELISA) plate reader (Tecan, Austria).

Terminal deoxynucleotidyl transferase (TdT) dUTP nick-end labeling (TUNEL) assay. TUNEL assay was performed by TdTFragELTM DNA fragmentation Detection Kit (Oncogene, Boston, MA, USA) according to the manufacturer's instructions. Briefly, cells were seeded in a chamber slide and incubated with $25 \mu \mathrm{M}$ of radachlorin described previously. After PDT, cells were incubated for 24 and $48 \mathrm{~h}$ and were fixed using $2 \%$ formaldehyde. After fixation, cells were permeabilized with $2.5 \%$ triton X-100 for $10 \mathrm{~min}$ and washed with PBS. TdT-Annexin V labeling reaction mixture in equilibrium buffer was added to specimens and incubation 


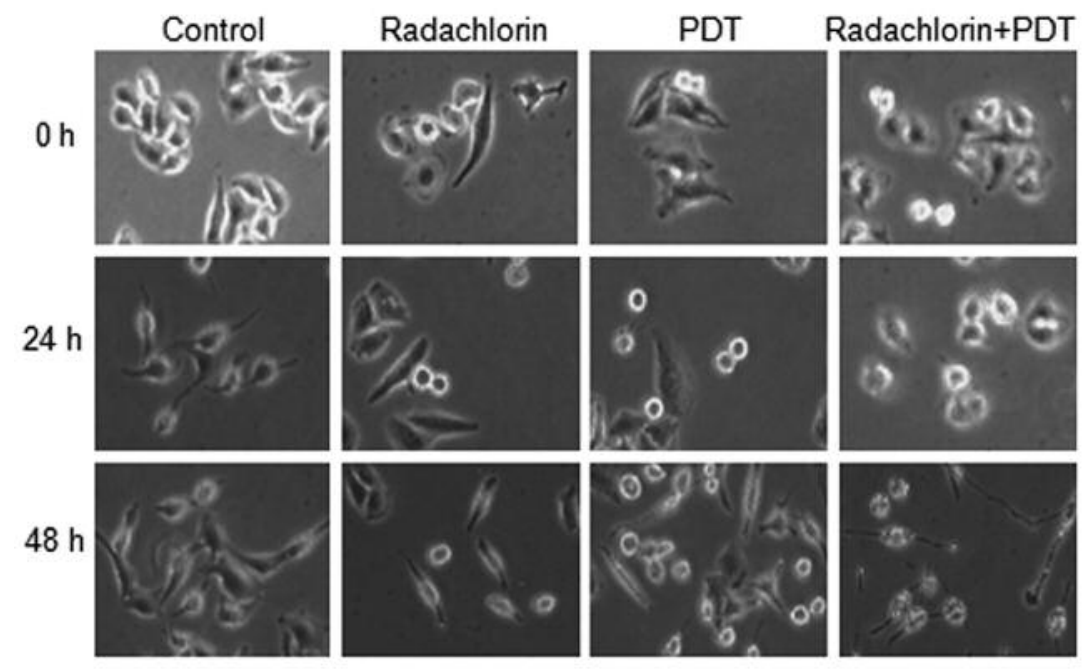

Figure 2. Morphological observation under an inverted microscope: the control cells grew adherently, showing clear contour. However, photodynamic therapy (PDT)-treated cells had altered morphology, showing condensed cytoplasm or floating behavior.

performed for $2 \mathrm{~h}$. After incubation, specimens were counterstained with $20 \mu \mathrm{g} / \mathrm{ml}$ of propidium iodide (PI) and annexin V-positive cells were observed by fluorescence microscope.

Tube formation assay. Plates were coated with matrigel (BD Biosciences, Bedford, MA, USA) by incubation at $37^{\circ} \mathrm{C}$ for $30 \mathrm{~min}$. Cells $\left(3 \times 10^{4}\right)$ were seeded with $50 \mathrm{ng} / \mathrm{ml}$ of recombinant human VEGF (Peptrotech, Rocky Hill, NJ, USA) onto the 24-well matrigel-coated plates. After $8 \mathrm{~h}$ incubation, cells were fixed with $2 \%$ formaldehyde and were stained with $2 \%$ crystal violet. Tube formation was observed under microscopy (BX51; Olympus) and total tube area was measured using Image $\mathrm{J}$ program $(\mathrm{NIH}$, Bethesda, MD, USA).

Invasion assay. The invasive ability of HEC-1-A cells was measured by the Boyden chamber invasion assay. Matrigel was applied to the top side of $8-\mu \mathrm{m}$ pore polycarbonate filters. In a Boyden chamber consisting of two chambers. A total of $30 \mu \mathrm{l}$ of medium from HEC1-A cells cultured for $24 \mathrm{~h}$ was applied in the lower chamber, and in the upper chamber, HEC-1-A cells were seeded at a density of $1 \times 10^{5}$ cells with or without $50 \mathrm{ng} / \mathrm{ml}$ of recombinant human VEGF (Peptrotech, Rocky Hill, NJ, USA). The chamber underwent PDT and was incubated for $8 \mathrm{~h}$ at $37^{\circ} \mathrm{C}$. At the end of incubation, the cells in the upper surface of the membrane were carefully removed with a cotton swab and cells that had invaded across the matrigel to the lower surface of the membrane were fixed with methanol and stained with $5 \%$ Giemsa solution. The invading cells on the lower surface of the membrane filter were counted with a light microscope. The data are presented as the average number of cells attached to the bottom surface from randomly chosen fields. Each experiment was carried out in triplicate.

Prostaglandin $E_{2}\left(P G E_{2}\right)$ assay. The expression level of PGE2 in cell culture medium was determined using an ELISA. Cell culture medium was collected from tube formation assay supernatant which was concentrated using centricon (Millipore, Temecula, CA, USA).
The ELISA kits were purchased from R\&D Systems (Minneapolis, MN, USA) and assays were performed according to the manufacturer's instructions and repeated in triplicate.

Western blot analysis. HEC-1-A cells were seeded at a density of $1 \times 10^{5}$ cells per well onto 6 wells with or without $50 \mathrm{ng} / \mathrm{ml}$ of recombinant human VEGF (Peptrotech, Rocky Hill, NJ, USA) before PDT. For western blot analysis, cell lysates were prepared with lysis buffer $[50 \mathrm{mM}$ Tris- $\mathrm{HCl}, \quad(\mathrm{pH}$ 7.5), $1 \mathrm{mM}$ ethylenediaminetetra-acetic acid, $150 \mathrm{mM} \mathrm{NaCl}, 10 \mu \mathrm{g} / \mathrm{ml}$ aprotinin, $10 \mu \mathrm{g} / \mathrm{ml}$ leupeptin, $10 \mu \mathrm{g} / \mathrm{ml}$ pepstatin A, $1 \mathrm{mM}$ phenylmethylsulfonyl fluoride, $1 \mathrm{mM}$ sodium fluoride, $10 \mathrm{mM}$ iodoacetamide, $1 \mathrm{mM}$ sodium orthovanadate] for $1 \mathrm{~h}$ on ice then centrifuged twice at $10,000 \times g$ for $15 \mathrm{~min}$. Equal amounts of lysates $(50 \mu \mathrm{g})$ were boiled in sodium dodecyl sulfate sample buffer and subjected to sodium dodecyl sulfate polyacrylamide gel electrophoresis (SDS-PAGE). After transfer, immuno-active products were detected by ECL system (GE, Piscataway, NJ, USA). Monoclonal antibodies to poly-(ADP-ribose) polymerase (PARP), caspase-9, VEGFR2, Ras homolog gene family/ member A (RhoA), and EGFR were obtained from Cell Signaling (Beverly, MA, USA). Mouse monoclonal antibody to $\beta$-actin (Sigma-Aldrich Corporation, St. Louis, MO, USA) was used as a loading control.

Statistical analysis. Results are expressed as the mean \pm S.D. The statistical significance of differences between the groups was determined by applying Student's $t$-test. Values of $p<0.05$ were considered statistically significant.

\section{Results}

The morphological observation of HEC-1-A cells after PDT. In order to investigate whether radachlorin-mediated PDT induced cell death, HEC-1-A cells were observed under an inverted microscope 24 and $48 \mathrm{~h}$ after treatment. As shown in 
Figure 2, the control cells grew adherently, showing a clear contour. However, PDT-treated cells had altered morphology, showing condensed cytoplasm or floating growth pattern within $24 \mathrm{~h}$.

Viability of HEC-1-A cells was reduced with PDT. The effect of different concentrations of radachlorin with PDT on HEC1-A cell viability was determined by MTT assay. Figure 3 shows that the viability of cells treated with radachlorin and PDT decreased on treatment with 12.5 to $200 \mu \mathrm{M}$ radachilorin. After $24 \mathrm{~h}$ incubation, the half-maximal inhibitory concentration $\left(\mathrm{IC}_{50}\right)$ for radachlorin was $55.4 \mu \mathrm{M}$, and after $48 \mathrm{~h}$ incubation, this was reduced to $20 \mu \mathrm{M}$. Based on these results, $25 \mu \mathrm{M}$ of radachlorin and 48-h incubation time were selected for further studies.

PDT induced apoptosis of HEC-1-A cells. TUNEL assay determines nuclear fragmentation by using TdT to transfer fluorescein-12-d UPT to free 3'-OH of cleaved DNA (16). Apoptotic cells produce fragmented nuclear DNA, which is stained brightly using annexin-V and PI labeling. From Figure 4, it can be seen that radachlorin-mediated PDT led to a significantly increased number of TUNEL-positive cells, implying that apoptosis was enhanced in comparison to controls. The effect of apoptosis was significantly stronger at $48 \mathrm{~h}$ incubation, compared to $24 \mathrm{~h}$ incubation.

Radachlorin-mediated PDT augmented the apoptosis signaling pathways. Caspases are cysteine proteases that are activated during the apoptotic signaling pathways. PARP belongs to a family of proteins mainly involving DNA repair and programmed cell death. Expression of PARP and caspase-9 were analyzed to study the involvement of the apoptosis signaling pathways. Expression of PARP and caspase-9 were significantly increased in VEGF-pretreated HEC-1-A cells treated with PDT in comparison to cells not pretreated with VEGF, as shown in Figure 5.

PDT reduced tubular formation of HEC-1-A cells. Tubular formation in endometrial cells has an important role in angiogenesis. VEGF induction of VEGFR results in tubular capillary formation in endometrial cells, which is related to cell invasion. The inhibitory effects of PDT on tubular formation in HEC-1-A cells were assessed using in vitro capillary-like structure (tube) formation assay. Cells treated with PDT alone showed a decrease in total tube area $(p=0.0029)$ compared to cells treated with VEGF alone (Figure 6). Interestingly, PDT treatment of VEGF-pretreated cells led to stronger inhibition of tubular formation in comparison to PDT of cells not pretreated with VEGF ( $p=0.0036)$ (Figure 6).

PDT suppressed invasion by HEC-1-A cells. Cancer cell invasion is an important step in metastasis. We investigated

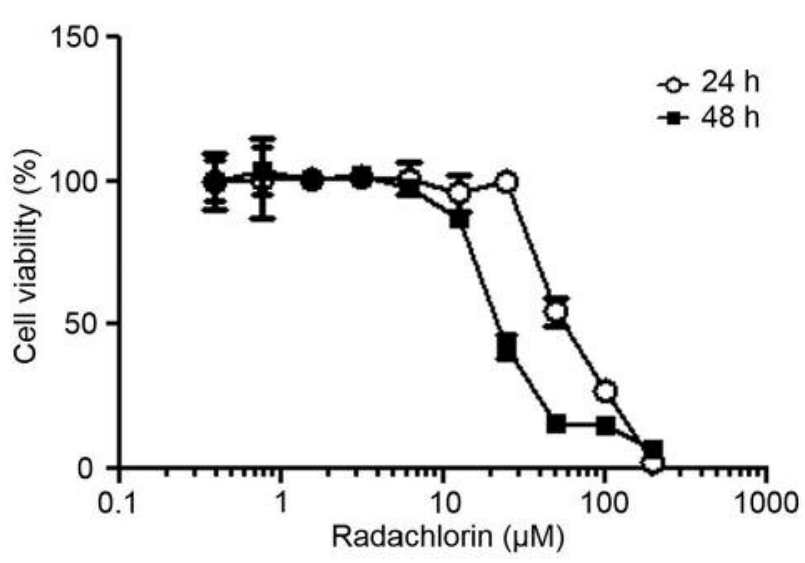

Figure 3. 3-(4,5-Dimethylthizol-2-yl)-2,5-diphenyltetrazolium bromide assay. Cell viability was reduced by increasing concentrations of radachlorin. Based on the results, $25 \mu \mathrm{M}$ of radachlorin and $48 \mathrm{~h}$ incubation time were selected for further studies.

the inhibitory effect of PDT on HEC-1-A invasiveness using a Boyden chamber. PDT blocked invasion by HEC-1-A cells, as compared to controls ( $p=0.0084)$ (Figure 7). Likewise, HEC-1-A invasiveness was markedly reduced by PDT in VEGF pretreated cells $(p=0.0087)$.

PDT reduced PGE2 production of HEC-1-A cells. PGE2 is a pro-inflammatory, mitogenic, and pro-angiogenic molecule. As shown in Figure 8, PGE2 levels decreased significantly in PDT-treated HEC-1-A cells $(p=0.0002)$. Likewise, the inhibitory effect of PDT was stronger in VEGF-pretreated cells $(p=0.0008)$.

Expression of EGFR, VEGFR2, and RhoA were reduced with radachlorin-mediated PDT. Expression of EGFR, VEGFR2 and RhoA were analyzed in order to investigate the antiangiogenic effects of PDT. As shown in Figure 9, expression of VEGFR2, EGFR and RhoA were reduced by PDT under VEGF pretreatment after $48 \mathrm{~h}$ incubation.

\section{Discussion}

PDT is an evolving modality for treating malignant neoplasms through its potential to eliminate microscopic cancer cells. Among gynecologic cancers, PDT is reportedly effective for cervical, vaginal, vulvar, and early endometrial cancers (15, 16, 23-27). PDT is less damaging to normal surrounding tissue, indicating enhanced tumor selectivity. Mirzaei et al. reported that HepG2, a hepatocellular carcinoma cell line, was more sensitive to the lethal effects of radachlorin- PDT than HFLF-PI4, a normal liver cell line (18). Therefore, PDT is a promising alternative for selective therapy of tumor cells. 
A

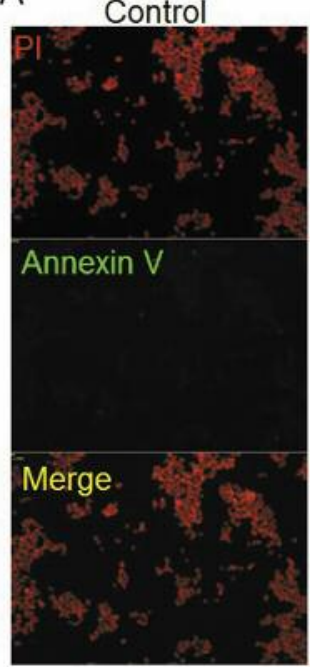

$24 \mathrm{~h}$

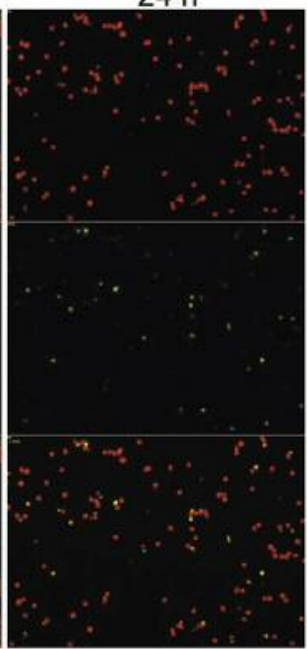

$48 \mathrm{~h}$

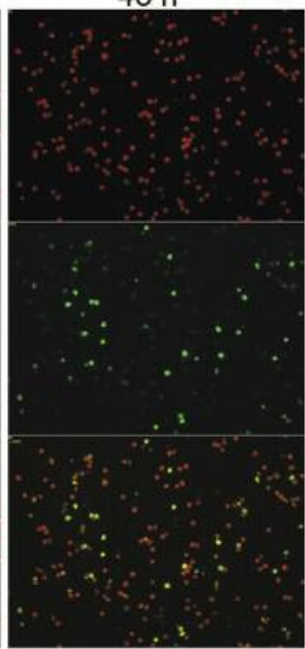

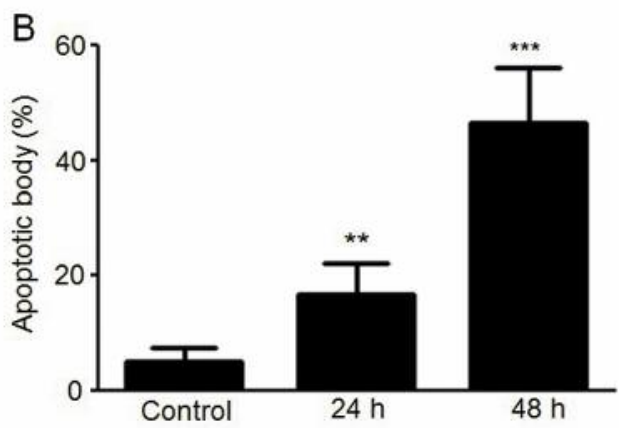

Figure 4. Terminal deoxynucleotidyl transferase dUTP nick end-labeling (TUNEL) assay. A: Cells were labelled with annexin-V and propidium iodide (PI) to study apoptosis. Radachlorin-mediated photodynamic therapy (PDT) led to a higher proportion of TUNEL-positive cells, implying that apoptosis was enhanced in comparison to controls. The effect on apoptosis was significantly stronger with 48-h incubation than 24-h incubation. $B$ : The histogram shows that the number of apoptotic cells increased significantly with radachlorin-mediated PDT. Significantly different from the control at $* * p=0.0026$ and $* * * p<0.0001$.

The objective of this study was to evaluate the efficacy of radachlorin-mediated PDT on HEC-1-A, a human endometrial adenocarcinoma cell line. We also investigated the signaling pathways involved in anticancer effects of radachlorinmediated PDT.

Our study suggests that radachlorin-mediated PDT significantly inhibited cell invasion and vascular formation, and enhanced apoptosis of HEC-1-A cells.

MTT and TUNEL assay showed that radachlorin-mediated PDT led to a higher number of apoptotic cells. Caspase- 9 is implicated as an initiator caspase, triggering the intrinsic pathway of apoptosis. Once activated, it leads to cleavage of various cytoplasmic or nuclear substrates, including PARP. Our western blot assay showed up-regulation of caspase-9 and PARP on treatment of HEC-1-A cells with radachlorinmediated PDT. These results indicate that the intrinsic pathway of apoptosis via caspase-9 and PARP through inhibition of EGFR/VEGFR2 is the main pathway by which apoptosis was induced by PDT in HEC-1-A cells.

Cell migration and invasion are landmark events that transform a locally growing tumor into a systemic, metastatic disease. Cancer invasion is a cell- and tissue-driven process by which the physical, cellular and molecular determinants adapt and react throughout disease progression (28). Angiogenesis, the formation of new blood vessels from preexisting vessels, is an essential process in malignant tumor invasion (29). Radachlorin-mediated PDT significantly

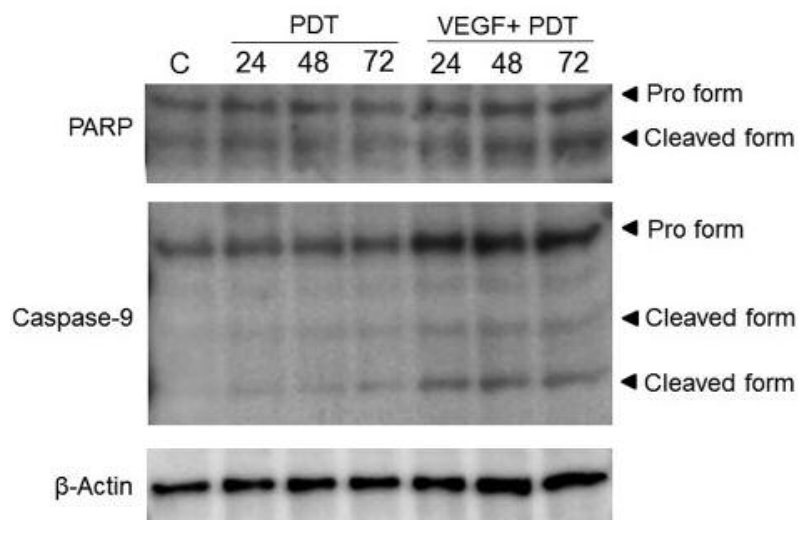

Figure 5. Western blot analysis of poly-(ADP-ribose) polymerase (PARP) and caspase-9. Expression of apoptosis pathway-related proteins PARP and caspase-9 was significantly increased in vascular endothelial growth factor (VEGF)- pretreated HEC-1-A cells treated with photodynamic therapy $(P D T)$ in comparison to cells not pretreated with VEGF. C: Untreated control cells.

reduced invasion and vascular formation by HEC-1-A-cells. Known regulatory mechanisms of angiogenesis include angiogenic induction with VEGF; however, recent studies indicate that the angiogenic response is more complex and may involve many factors (30). Among the many angiogenic 

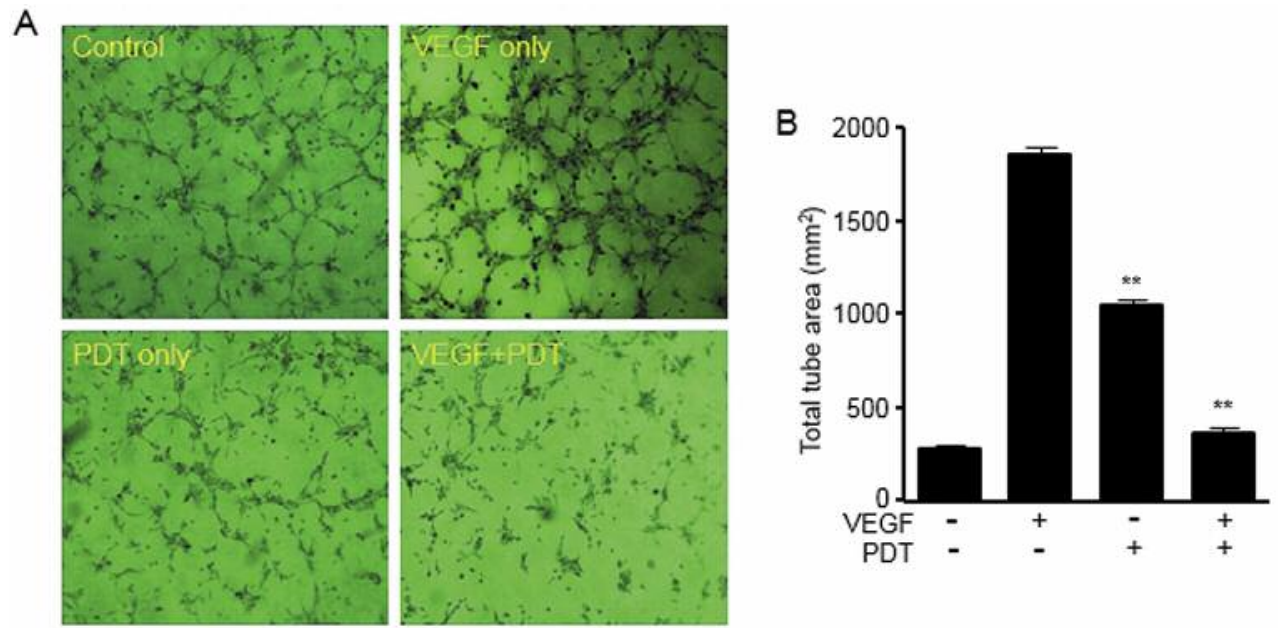

Figure 6. Tube formation assay. A: Measuring the area of capillary-like structures under microscopy (x20) shows inhibitory effects on tubular formation by photodynamic therapy (PDT). B: PDT led to a decrease in total tube area, as compared to control. Interestingly, PDT treatment in vascular endothelial growth factor (VEGF)-pretreated cells showed stronger inhibition of tubular formation in comparison to cells not pretreated with VEGF.
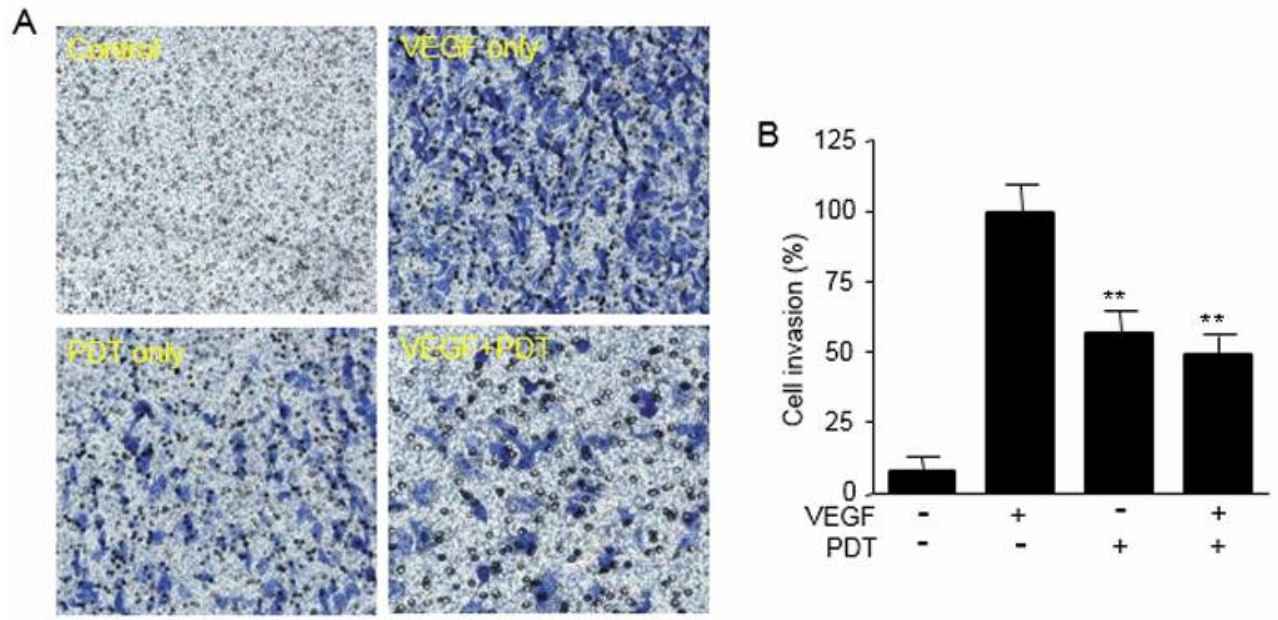

Figure 7. Invasion assay. A: Invasive cells on the lower surface of the membrane filter as seen using a light microscope $(\times 40)$. B: Photodynamic therapy (PDT) significantly blocked invasion by HEC-1-A cells compared to controls. HEC-1-A invasiveness was markedly reduced by PDT in vascular endothelial growth factor (VEGF)-pretreated cells.

factors, VEGFR2, EGFR, PGE2 and RhoA were selected in our study. PGE2, the predominant prostaglandin in solid tumors, is synthesized in cancer epithelial, blood vessel endothelial, and immune cells (31). PGE2 exerts its effects in an autocrine and paracrine fashion and affects cancer cell growth, survival, and migration (32). Available evidence suggests that PGE2 might induce proangiogenic factors, such as VEGF, which initiate angiogenesis of endothelial cells. Our results showed that radachlorin-mediated PDT suppressed PGE2 production of HEC-1-A cells. The VEGFR/EGFR signaling pathway is critical for endothelial cell proliferation, migration, cell survival and for the induction of vascular permeability (33).

One of the small GTPases, RhoA, controls a diverse array of cellular processes, including cytoskeletal dynamics, cell polarity, membrane transport, and gene expression (34). Rho signaling is reportedly essential for VEGF dependent in vivo angiogenesis and in vitro capillary formation (35-37). With 


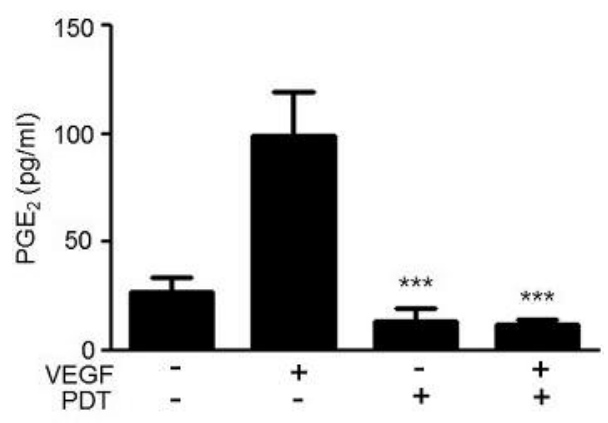

Figure 8. Prostaglandin E2 (PGE2) assay showed PGE 2 expression significantly decreased in photodynamic therapy (PDT)-treated HEC1-A cells. The inhibitory effect of PDT was stronger in cells treated with vascular endothelial growth factor (VEGF).

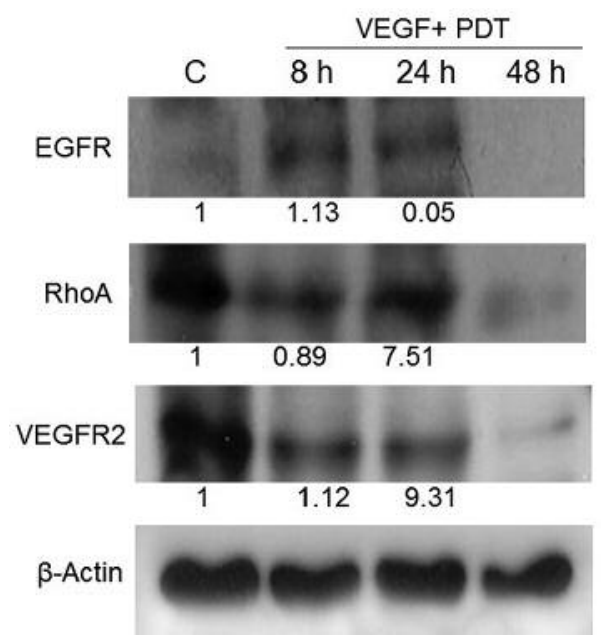

Figure 9. Western blot analysis of epidermal growth factor receptor (EGFR), Ras homolog gene family/ member A (RhoA), and vascular endothelial growth factor receptor-2 (VEGFR2). Expression of VEGFR2, EGFR and RhoA were inhibited by PDT after $48 \mathrm{~h}$ incubation under pretreatment with VEGF. The expression folds comparing untreated cells (C) were measured using Image $J$, and normalized with $\beta$-actin.

certain angiogenic signals including VEGF, RhoA is converted from its inactive (GDP-bound) to active form (GTP-bound) via catalysis from certain Rho guanine nucleotide exchange factors (38). Brad et al. suggested that Rho inhibition blocks VEGF-driven vessel formation (39). In our study, results from western blot analysis showed down-regulation of VEGFR2, EGFR and RhoA, which suggests that radachlorin-mediated PDT inhibits multiple pathways involved in cancer invasion and vascular formation. Interestingly, tube formation and invasion assay results showed strong anticancer effects on cells pretreated with VEGF, indicative of the specificity of radachlorinmediated PDT to VEGF-expressing cells.
Therefore, different signaling pathways were modulated in radachlorin-mediated PDT. Firstly, the angiogenic pathway was suppressed by inhibition of VEGFR2, EGFR, PGE2, and RhoA. Secondly, intrinsic apoptosis was activated via caspase- 9 and PARP.

These findings could be of importance in developing PDT as a fertility-preserving therapy for patients with gynecolgical cancer.

\section{Conflicts of Interest}

The Authors declare that they have no conflict of interest in regard to this study.

\section{References}

1 Lim MC, Moon EK, Shin A, Jung KW, Won YJ, Seo SS, Kang S, Kim JW, Kim JY and Park SY: Incidence of cervical, endometrial, and ovarian cancer in Korea 1999-2010. J Gynecol Oncol 24: 298-302, 2013.

2 Siegel R, Naishadham D and Jemal A: Cancer statistics 2013. CA Cancer J Clin 63: 11-30, 2013.

3 Rose PG: Endometrial carcinoma. N Engl J Med 335: 640-649, 1996.

4 Amant F, Moerman P, Neven P, Timmerman D, Van Limbergen E and Vergote I: Endometrial cancer. Lancet 366: 491-505, 2005.

5 Akimasa T, Fuminori K, Akiyoshi Y, Akie T, Nobuyuki K, Kentaro $\mathrm{T}$ and Takashi $\mathrm{M}$ : Metformin impairs growth of endometrial cancer cells via cell-cycle arrest and concomitant autophagy and apoptosis. Cancer Cell Int 14: 53, 2014.

6 Choi MC, Jung SG, Park H, Cho YH, Lee C and Kim SJ: Fertility preservation via photodynamic therapy in young patients with early-stage uterine endometrial cancer: a long-term follow-up study. Int J Gynecol Cancer 23: 698-704, 2013.

7 Gerber HP, McMurtrey A, Kowalski J, Yan M, Keyt BA, Dixit $\mathrm{V}$ and Ferrara N: Vascular endothelial growth factor regulates endothelial cell survival through the phosphatidylinositol 3'kinase/AKT signal transduction pathway. Requirement for Flk1/KDR activation. J Biol Chem 273: 30336-30343, 1998.

8 Takahashi T, Ueno $\mathrm{H}$ and Shibuya M: VEGF activates protein kinase C-dependent, but RAS-independent RAF-MEK-MAP kinase pathway for DNA synthesis in primary endothelial cells. Oncogene 18: 2221-2230, 1999.

9 Yarden Y: The EGFR family and its ligands in human cancer. signalling mechanisms and therapeutic opportunities. Eur J Cancer 37(Suppl 4): S3-8, 2001.

10 Ferrara N, Gerber HP and LeCouter J: The biology of VEGF and its receptors. Nat Med 9: 669-675, 2003.

11 Nicholson RI, Gee JM and Harper ME: EGFR and cancer prognosis. Eur J Cancer 37(Suppl 4): S9-15, 2001.

12 Yang F, Tang X, Riquelme E, Behrens C, Nilsson MB, Giri U, Varella-Garcia M, Byers LA, Lin HY, Wang J, Raso MG, Girard L, Coombes K, Lee JJ, Herbst RS, Minna JD, Heymach JV and Wistuba II: Increased VEGFR2 gene copy is associated with chemoresistance and shorter survival in patients with non-smallcell lung carcinoma who receive adjuvant chemotherapy. Cancer Res 71: 5512-5521, 2001. 
13 Pal HC, Sharma S, Strickland LR, Agarwal J, Athar M, Elmets CA and Afaq F: Delphinidin reduces cell proliferation and induces apoptosis of non-small-cell lung cancer cells by targeting EGFR/VEGFR2 signaling pathways. PLoS One 8: e77270, 2013.

14 Hopper C: Photodynamic therapy: a clinical reality in the treatment of cancer. Lancet Oncol 1: 212-219, 2000.

15 Ehrlich CE, Young PC, Stehman FB, Sutton GP and Alford WM: Steroid receptors and clinical outcome in patients with adenocarcinoma of the endometrium. Am J Obstet Gynecol 158: 796-807, 1988.

16 Qiang YG, Zhang XP, Li J and Huang Z: Photodynamic therapy for malignant and non-malignant diseases: clinical investigation and application. Chin Med J (Engl) 119: 845-857, 2006.

17 Robertson CA, Evans DH and Abrahamse H: Photodynamic therapy (PDT): a short review on cellular mechanisms and cancer research applications for PDT. J Photochem Photobiol B 96: 1-8, 2009.

18 Mirzaei H, Djavid GE, Hadizadeh M, Jahanshiri-Moghadam M and Hajian P: The efficacy of Radachlorin-mediated photodynamic therapy in human hepatocellular carcinoma cells J Photochem Photobiol B 142: 86-91, 2015.

19 Kochneva EV, Filonenko EV, Vakulovskaya EG, Scherbakova EG, Seliverstov OV, Markichev NA and Reshetnickov AV: Photosensitizer Radachlorin ${ }^{\circledR}$ : Skin cancer PDT phase II clinical trials. Photodiagnosis Photodyn Ther 7: 258-267, 2010.

20 Bae SM, Kim YW, Lee JM, Namkoong SE, Han SJ, Kim JK, Lee $\mathrm{CH}$, Chun HJ, Jin HS and Ahn WS: Photodynamic effects of Radachlorin on cervical cancer cells. Cancer Res Treat 36: 389-394, 2004.

21 Filonenko EV, Sokolov VV, Chissov VI, Lukyanets EA and Vorozhtsov GN: Photodynamic therapy of early esophageal cancer. Photodiagnosis Photodyn Ther 5: 187-190, 2008.

22 Venugopal $\mathrm{J}$ and Blanco G: Ouabain enhances ADPKD cell apoptosis via the intrinsic pathway. Front Physiol 7: 107.eCollection, 2016.

23 Hillemanns P, Wang X, Staehle S, Michels W and Dannecker C: Evaluation of different treatment modalities for vulvar intraepithelial neoplasia (VIN): $\mathrm{CO}(2)$ laser vaporization, photodynamic therapy, excision and vulvectomy. Gynecol Oncol 100: 271-275, 2006.

24 Krimbacher E, Zeimet AG, Marth $\mathrm{C}$ and Kostron H: Photodynamic therapy for recurrent gynecologic malignancy: a report on 4 cases. Arch Gynecol Obstet 262: 193-197, 1999.

25 Lele SB, Piver MS, Mang TS, Dougherty TJ and Tomczak MJ: Photodynamic therapy in gynecologic malignancies. Gynecol Oncol 34: 350-352, 1989.

26 Rettenmaier MA, Berman ML, Disaia PJ, Burns RG and Berns MW: Photoradiation therapy of gynecologic malignancies. Gynecol Oncol 17: 200-206, 1984.
27 Yamaguchi S, Tsuda H, Takemori M, Nakata S, Nishimura S, Kawamura N, Hanioka $\mathrm{K}$, Inoue $\mathrm{T}$ and Nishimura $\mathrm{R}$ : Photodynamic therapy for cervical intraepithelial neoplasia. Oncology 69: 110-116, 2005.

28 Friedl $\mathrm{P}$ and Alexander S: Cancer invasion and the microenvironment: plasticity and reciprocity. Cell 147: 992-1009, 2011.

29 Lee SH, Jeong D, Han YS and Baek MJ: Pivotal role of vascular endothelial growth factor pathway in tumor angiogenesis. Ann Surg Treat Res 89: 1-8, 2015.

30 Hanahan D and Weinberg RA: Hallmarks of cancer: the next generation. Cell 144: 646-674, 2011.

31 Wang D and Dubois RN: Eicosanoids and cancer. Nat Rev Cancer 10: 181-193, 2010.

32 Legler DF, Bruckner M, Uetz-von Allmen E and Krause P: Prostaglandin $E_{2}$ at new glance: novel insights in functional diversity offer therapeutic chances. Int J Biochem Cell Biol 42: 1 98-201, 2010.

33 Ciardiello F, Troiani T, Bianco R, Orditura M, Morgillo F, Martinelli E, Morelli MP, Cascone T and Tortora G: Interaction between the epidermal growth factor receptor (EGFR) and the vascular endothelial growth factor (VEGF) pathways: a rational approach for multi-target anticancer therapy. Ann Oncol 17: 109114, 2006.

34 Jaffe $\mathrm{AB}$ and Hall A: Rho GTPases: biochemistry and biology. Annu Rev Cell Dev Biol 21: 247-269, 2005.

35 Connolly JO, Simpson N, Hewlett L and Hall A: Rac regulates endothelial morphogenesis and capillary assembly. Mol Biol Cell 13: 2474-2485, 2002.

36 Hoang MV, Whelan MC and Senger DR: Rho activity critically and selectively regulates endothelial cell organization during angiogenesis. Proc Natl Acad Sci USA 101: 1874-1879, 2004.

37 Park HJ, Kong D, Iruela-Arispe L, Begley U, Tang D and Galper JB: 3-hydroxy-3-methylglutaryl coenzyme A reductase inhibitors interfere with angiogenesis by inhibiting the geranylgeranylation of RhoA. Circ Res 91: 143-150, 2002.

38 Hakoshima T, Shimizu T and Maesaki R: Structural basis of the Rho GTPase signaling. J Biochem 134: 327-331, 2003.

39 Bryan BA, Dennstedt E, DC, Walshe TE, Noma K, Loureiro R, Saint-Geniez M, Jean-Paul Campaigniac J-P, Liao JK and D'Amore PA: RhoA/ROCK signaling is essential for multiple aspects of VEGF-mediated angiogenesis. FASEB J 24: 31863195,2010 